controlled the oxidation of the coal substance; at about $70^{\circ}-80^{\circ} \mathrm{C}$ its breakdown could lead to rapid oxidation and with certain fuels to spontaneous ignition. At com. bustion temperatures the presence of a layer, defined as oxycarbon, was an important factor in the combustion process.

Reviewing the overall picture, Dr. Townend pointed out that in the practical field a matter of importance was the control of the aerodynamies of a combustion system to provide adequate mixing of solid particles with the reactant gases, including hydrogen, carbon dioxide, water and atoms and radicals; for gasification and oxidation were mutually involved. He also considered the likely advantages to be gained by combustion under pressure, having regard to the chemical and physical factors involved.

In conclusion, Dr. Townend emphasized that many combustion phenomena accepted to-day as commonplace would not have been predicted forty years ago; and as an illustration he mentioned the manner of his discovery of the two-stage process of the ignition of hydrocarbons which had proved the key to the elucidation of the problem of 'knock' in internal combustion engines.

After the lecture a dinner in honour of Dr. Townend was held at the Savoy Hotel; at this function the Coal Science Medal was presented to Dr. Townend by Mr. E. H. Browne, president of the British Coal Utilization Research Association.

\title{
A CHANNEL LINK
}

A LTHOUGH the report of the working group of British and French officials on Proposals for a Fixed Channel Link* was published two months later than the Broadsheet Transport in the Common Market, issued by Political and Economic Planning in July $\dagger$, it is significent that in the Broadsheet Mrs. Trench makes no reference at all to either a tunnel or a bridge for the English Channel. After indicating the three objectives of a common transport-removal of obstacles which transport would offer to the establishment of the general Common Market; creation of healthy competition of the widest possible scope; provision of means of transport meeting in quantity and in quality the requirements of the European Economic Community- the Broadsheet reviews the measures proposed. These include a tariff policy for freight, and after considering the general proposals the Broadsheet considers international transport by road and the domestic road transport of goods.

The investigation finds that there is still no sign of an agreement between member States on the proposals or even of the policy being implemented in 1963-65, and it is unlikely that there will be any substantial progress towards implementing a common policy until after this. The proposals in the Action Programme for the Common Transport Policy presented to the Council of Ministers in May 1963 are themselves the result of compromises between conflicting objectives of the policy and also between existing practices in the member States; they are so framed that they stand some chance of being acceptable to all the countries in spite of the differences between their present transport systems. The objectives of the policy are much more ambitious and extensive than the minimum necessary to secure the free working of the Common Market, and the instruments chosen, notably the system of forked tariffs, have far-reaching implica. tions. Nevertheless, some of the major transport problems are left untouched. Own-account transport of goods is left free to develop in a way which could well frustrate the objectives of the policy to secure an optimal use of transport facilities of the Community as a whole. There are no proposals about private cars, although the growth in their numbers and the pattern of their use affect road expenditure and traffic congestion, and thus the cost of operating goods vehicles, as well as the passenger revenue of the railways, the size of the railway system and its costs of provision.

Any attempt to secure a real improvement in a com. munity's use of transport resources should, the Broad. sheet points out, rest on a full investigation of the social benefits and costs of transport operations, and the Commission is at present studying 'infra-structure costs' in

* Ministry of Transport. Proposals for a Fixed Channel Link. Pp. Iv +60. (Cmnd. 2147.) (London: H.M.S.O., 1963.) 6s. 6d. net.

+ Planning, Vol. 29, No. 473 (8 July, 1963). Transport in the Common Market. Pp. 223-286, By Sylvia Trench. (London: Political and Economic Planning. 1963.) 68. order to reconstruct the basis of taxation on different forms of transport to redistribute the burden of Government expenditure as between different users. It is suggested that the Commission should broaden these investigations to take into account costs and benefits dispersed among the community as a whole as a result of the expansion or contraction of different kinds of transport. Policy could then be based on a much better knowledge of what different developments are likely to cost the community in terms of lost amenities, increased congestion, reduced scope and frequency of public services, etc.

This kind of consideration is lacking in the report on the proposals for a Channel tunnel and Channel bridge. Unfortunately, the report is also markedly lacking in either imagination or enthusiasm, and it appears to be preoccupied with financial and economic considerations in the narrower sense to the exclusion of social and political and even technical aspects whether short or long term. Charged with considering the project for a tunnel proposed in March 1960 by the Channel Tunnel Study Group and the project for a bridge proposed in October 1961 by the Channel Bridge Study Group, its findings are in favour of the rail tunnel project. It finds this means satisfactory from the technical point of view and constituting from the economic point of view a preferable solution to the continued use and development of established means of transport, while at the same time being free from the practical disadvantages of the bridge-which is likely to have a capital cost almost double. The working group foresees no increase in traffic or other advantage to offset this higher cost, and even the financing of the rail tunnel it regards as an uncertain risk and recommends that the two Governments should contemplate direct guarantee of loans, but also that the bounds of the privately owned undertaking should be guaranteed. This would be a new departure in United Kingdom practices and one that in France is only used on an extremely limiter scale.

It is recognized that the bridge, which offers a continuous road and rail Channel link in the open, is a more attractive proposal to road users than the tunnel project, in which vehicles are driven on and off special car ferry trains operating at intervals of $5-30 \mathrm{~min}$ according to demand, carrying either 150 or 300 cars, and completing the journey in an average of $65 \mathrm{~min}$, of which $45 \mathrm{~min}$ would be occupied by the journey proper. The working party regards the bridge as offering a new and serious hazard and source of delay to shipping; also its construction would involve international agreement as to safety regulations for sea traffic as well as to the bridge in principle. It does not consider that these objections would be removed by foreseeable developments in navigational aids within the next few years. However, it did not seriously consider a third proposal, for an immersed road-rail tunnel, which was submitted in March 1963 and for which the capital cost is estimated to be $£ 236$ million, compared 
with $£ 329$ million for the bridge and $£ 160$ million for the rail tunnel.

The proposals for a bridge and for a road tunnel both rely largely on tax reliefs to improve the financial prospects of their respective projects, but the risks do not appear to be excessively high, and while the means of Government assistance here proposed may be open to objection. the decision as to whether the projert should be supported or not is one for Government level. The decision, moreover, is urgent and ought not to be postponed. If the determining considerations are those that fall outside the scope of the working party itself, and even if the proposals represent little that could not have been advanced half a century or more earlier, to delay is only to increase the ultimate cost of a favourable decision-a cost that has multiplied many times since the proposal was first advanced in the last century (see, for example, Nature, $1,160,303,631 ; 1869)$.

\section{EMPLOYMENT OF WOMEN IN INDUSTRY}

\begin{abstract}
A RECENT investigation of the industrial employ ment of women throughout their middle working lives*, to which the Director of the Nuffield Foundation contributes a foreword, is essentially in continuation of the investigations which the Foundation has for some time been promoting on the employment prospects of older men. Insisting that the basic unit of society is the indissoluble complex of relationships that controls both men and women, $\mathrm{Mr}$. Le Gros Clark takes account of this subtle but changing element in dealing with the influx of women into employment. Considering first the life rhythms of modern women, he concludes that there will be far fewer single women in middle life and a diminishing number of widows, though this large impact of widowhood will not be felt until most married women are passing beyond their employable age. Of necessity, if employers still need female labour, they will have to depend on married women, and mostly on those of mature years. Moreover, Mr. Le Gros Clark insists also on the importance of the contribution which married women and mothers make outside the labour market; he regards as misleading the classification of many women by economists as merely 'dependants'. Women as a whole are not free to go out to work until they feel that they have among them accounted for their multifarious domestic and family commitments.
\end{abstract}

His analysis of available and relevant figures of parttime employment indicates that age makes remarkably little difference in the opportunities most women have of limiting the hours they work, and that the older women still have their domestic commitments as well as some impairment of health in mind when they stipulate for a part-time job. Most of them would also seem to take it for granted that at their age they may have to gravitate to a catering, domestic or cleaning job. Now that working hours per week are contracting in most industries, the stipulations made by many married women seem likely to appear more realistic. It is not easy to say at what

* Woman, Work and Age: To Study the Emploument of Working Women Throughout Their Middle Lives. By F. Le Gros Clark. Pp. 111 (London: The Nuffield Foundation, 1963.) 7s. 6 d. net. ages and for what reasons women finally move out of the labour market, but, in the present state of medical knowledge, women seem more susceptible than men to the kinds of ailment which one might expect to hasten their withdrawal from work outside their homes.

Their rates of withdrawal from the manufacturing industries are most noticeable, and while the possibility of moving the older married women to lighter or modified work requires examination, it can at least be said that, although most middle-aged women are not on such exacting work, the differential withdrawal rate among those who are could easily affect the average rate at which women leave employment. At present they do so in substantial numbers in their early fifties, and probably nearly one in three has departed by the time they approach sixty. Some leave by choice and some subject to retirement regulations, but a proportion which is not negligible complain of industrial strain or incipient ill-health, so that women still at work in their late sixties represent only about a quarter of those who are at work ten years younger, and most are working on their own or managing the work of others, or in some 'domestic' form of employment.

Mr. Le Gros Clark suggests some of the female-male adjustments that are likely to be needed particularlv if middle-aged married women are required in employment. In large measure he predicts they will be able to make their own terms, particularly about their hours of work. This is likely to be felt particularly in health, welfare and educational services, but he suggests too that the amenities, the codes of behaviour and the conventions habitual through industry are likely to be affected ultimately. He points to the desirability, in the general education of girls, of making an effort to break down the barrier between the sciences and the arts and of stressing the æsthetic qualities of the former subjects. This is largely a matter of finding imaginative teachers, but it has a great bearing on equipping girls for life, especially as, ultimately, married women may have to show them. selves more prepared to take on posts of skill and responsibility.

\section{SCIENTIFIC RESEARCH IN BELGIUM}

T HE annual report for 1962 of the National Council for Scientific Policy, Brussels*, is of special interest in view of the present discussions on scientific policy in Western Europe generally. Moreover, it exemplifies the type of report which the Office of the Ministry for Science might be expected to provide regularly for the United Kingdom and which, on a lesser scale, the annual report of the Advisory Council on Scientific Policy has some. times supplied in part. Following an introduction, the report is in two parts: the first outlines the functions of the Council, including the general structure of scientific

- Conseil National de Ia Politique Scientiflque. Rapport Annuel, 1962. Pp. 171. (Bruxelles: Conseil National de la Politique Scientiflque, 1963.) work in Belgium; the second records the activities of the Council during December 1, 1961-December 1, 1962, including those of its committeos and institutions and Government measures affecting the work of the Council. Among appendixes which list the membership of various committees, etc., is a note on the meeting of the Ministerial Committee for Scientific Policy and the Bureau of the Council last July at which the Budget for 1963 was fixed at 4,904 million franes, a 20 per cent increase on the previous year, and including an 18 per cent increase for the universities.

The first part of the report is of the most general interest. The budget for 1962 was for 4,080 million francs, an increase of 14.4 per cent over 1961. Of this, 2,316 